\title{
Senile Nephrosclerosis - Does It Explain the Decline in Glomerular Filtration Rate with Aging?
}

\author{
Andrew D. Rule ${ }^{a} \quad$ Lynn D. Cornell ${ }^{b}$ Emilio D. Poggio ${ }^{c}$ \\ a Division of Nephrology and Hypertension and Division of Epidemiology, and b Division of Anatomic Pathology, \\ Mayo Clinic, Rochester, Minn., and 'Department of Nephrology and Hypertension, Glickman Urological and \\ Kidney Institute, Cleveland, Ohio, USA
}

\section{Key Words}

Aging $\cdot$ Glomerular filtration rate $\cdot$ Nephrosclerosis

\begin{abstract}
Nephrosclerosis can be defined by the presence of glomerulosclerosis, tubular atrophy, interstitial fibrosis, and arteriosclerosis on renal biopsy. Chronic kidney disease is identified clinically by a reduction in glomerular filtration rate (GFR) and has been characterized histologically by nephrosclerosis. Many relatively healthy older adults have been diagnosed with chronic kidney disease because of a decline in GFR with normal aging. Recent data show that in healthy adults (living kidney donors), nephrosclerosis on renal biopsy does not associate with GFR independent of age. This may be explained by the decline in GFR and nephrosclerosis being universal with aging (i.e. senescence), by structural changes in the kidney other than nephrosclerosis impacting GFR, or by extrarenal factors affecting GFR decline with age. However, the argument that the age-related decline in GFR can be fully explained by the development of nephrosclerosis in a subset of older adults is not supported by existing data.

Copyright $\odot 2011$ S. Karger AG, Basel
\end{abstract}

Among cardiovascular risk factors, estimated glomerular filtration rate (GFR) is the most strongly correlated with age $(r=-0.76)$ [1]. Consequently, a large proportion of elderly persons have an estimated GFR less than $60 \mathrm{ml} /$ $\min / 1.73 \mathrm{~m}^{2}$, which has been used to define chronic kidney disease (CKD) [2]. As a consequence of this CKD classification scheme, age-related decline in GFR is viewed as a clinical kidney disease. There is no distinction made between GFR decline with age in healthy populations (e.g. kidney donors) from GFR decline with age due to specific disease processes more common in the elderly (e.g. diabetic nephropathy). Reduced GFR predicts increased mortality, but there is also effect modification by age. Specifically, the threshold for increased mortality risk occurs at a lower estimated GFR in older compared to younger adults [3]. This raises the following questions: are all reductions in GFR with age reflective of underlying pathological injury in the kidney? In particular, does a decline in GFR by $10 \%$ with aging occur because $10 \%$ of the glomeruli become globally sclerosed? The serial renal histology for an age-related decline in GFR would be informative, but the vast majority of persons with mild to moderate reductions in GFR $\left(45-89 \mathrm{ml} / \mathrm{min} / 1.73 \mathrm{~m}^{2}\right)$

\section{KARGER}

Fax +41613061234 E-Mail karger@karger.ch www.karger.com
(C) 2011 S. Karger AG, Basel

Accessible online at: www.karger.com/nep
Andrew D. Rule

Mayo Clinic, 200 1st Street SW

Rochester, MN 55905 (USA)

Tel. +1 507266 1045, E-Mail rule.andrew@ mayo.edu 
Fig. 1. Mosaic plot of sclerosis scores by age group among 1,203 living kidney donors. Sclerosis score defined as the total number of chronic histological abnormalities between (1) any global glomerulosclerosis, (2) any tubular atrophy, (3) interstitial fibrosis $>5 \%$ and (4) any arteriosclerosis. In the figure, a score of 0 is white, a score of 4 is black, and intermediate scores are on a gray scale. Width of each age group is proportional to the sample size [10].

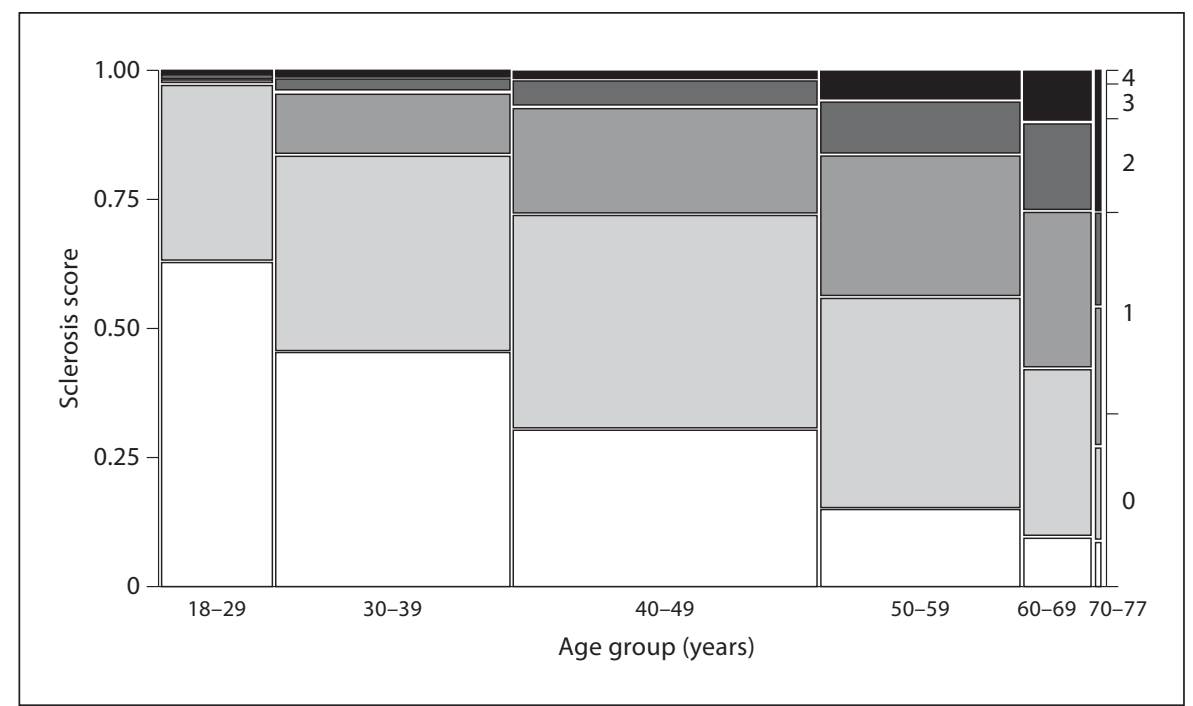

never undergo a renal biopsy. The rate of renal biopsy in the general population is approximately 2 per 10,000 person-years and is limited to a select group of patients $[4,5]$. Thus, the underlying renal parenchymal characteristics for most with presumed CKD in the general population (13\% of adults) [2] is unclear, creating uncertainty with systematically considering all GFR decline as kidney disease.

The morphologic changes seen in the aging kidney can be described as nephrosclerosis, a term that often refers to parenchymal changes with hypertension. The classic textbook, Robbins and Cotran Pathological Basis of Disease, distinguishes 'benign' from 'malignant' nephrosclerosis, with the latter characterized by onion-skinning of arteries secondary to accelerated hypertension. Benign nephrosclerosis is described as 'the renal pathology associated with sclerosis of renal arterioles and small arteries. The resultant effect is focal ischemia of parenchyma supplied by vessels with thickened walls and consequent narrowed lumens. The parenchymal effects include glomerulosclerosis and chronic tubulointerstitial injury, producing a reduction in functional renal mass' [6]. However, there is uncertainty as to whether luminal narrowing from arteriosclerosis is actually causal for glomerulosclerosis or whether other undefined factors lead to both [7]. Systematic study of nephrosclerosis has been difficult as the entity is often tied to hypertension even though the same histological findings occur in normotensive older adults [8-10]. Moreover, nephrosclerosis in the aging kidney is not necessarily related only to blood pressure and vascular disease.

Senile Nephrosclerosis - Does It Explain the Decline in GFR with Aging?
Nephrosclerosis can be identified in kidneys by several different methods: gross appearance of a leathery granular kidney surface at autopsy, reduced kidney volume on an imaging study, or histologic findings from a cortical renal biopsy. On renal histology, glomerulosclerosis, tubular atrophy, interstitial fibrosis and arteriosclerosis often occur together, and become more common with aging (fig. 1, 2) [7, 10]. An operational definition for nephrosclerosis is the presence of two or more of these chronic histological abnormalities on a sectioned standard needle core biopsy [10]. These microanatomical changes of tubular atrophy and glomerulosclerosis with aging may account for the macroanatomical reduction in kidney size by $10 \%$ per decade of age seen on the computed tomographic scans of adults (fig. 3) [11].

Global glomerulosclerosis with aging may seem particularly relevant to the decline in GFR with aging. After all, GFR is the sum of the single-nephron GFRs for all functioning glomeruli, which would exclude globally sclerosed glomeruli. The process leading to global glomerulosclerosis as a result of vascular compromise is not fully understood. Affected glomeruli develop increased basement membrane thickening and wrinkling and there is shrinkage of the glomerular tuft towards the vascular pole on light microscopy, along with periglomerular fibrosis [12]. There is eventual global sclerosis of the glomerular tuft with collagen deposition that fills Bowman's space [9]. There may be eventual absorption of these sclerosed glomeruli since the total number of glomeruli in the kidney decreases with older age [13]. Alternatively, sclerotic glomeruli may be under-represented on sections due to their 


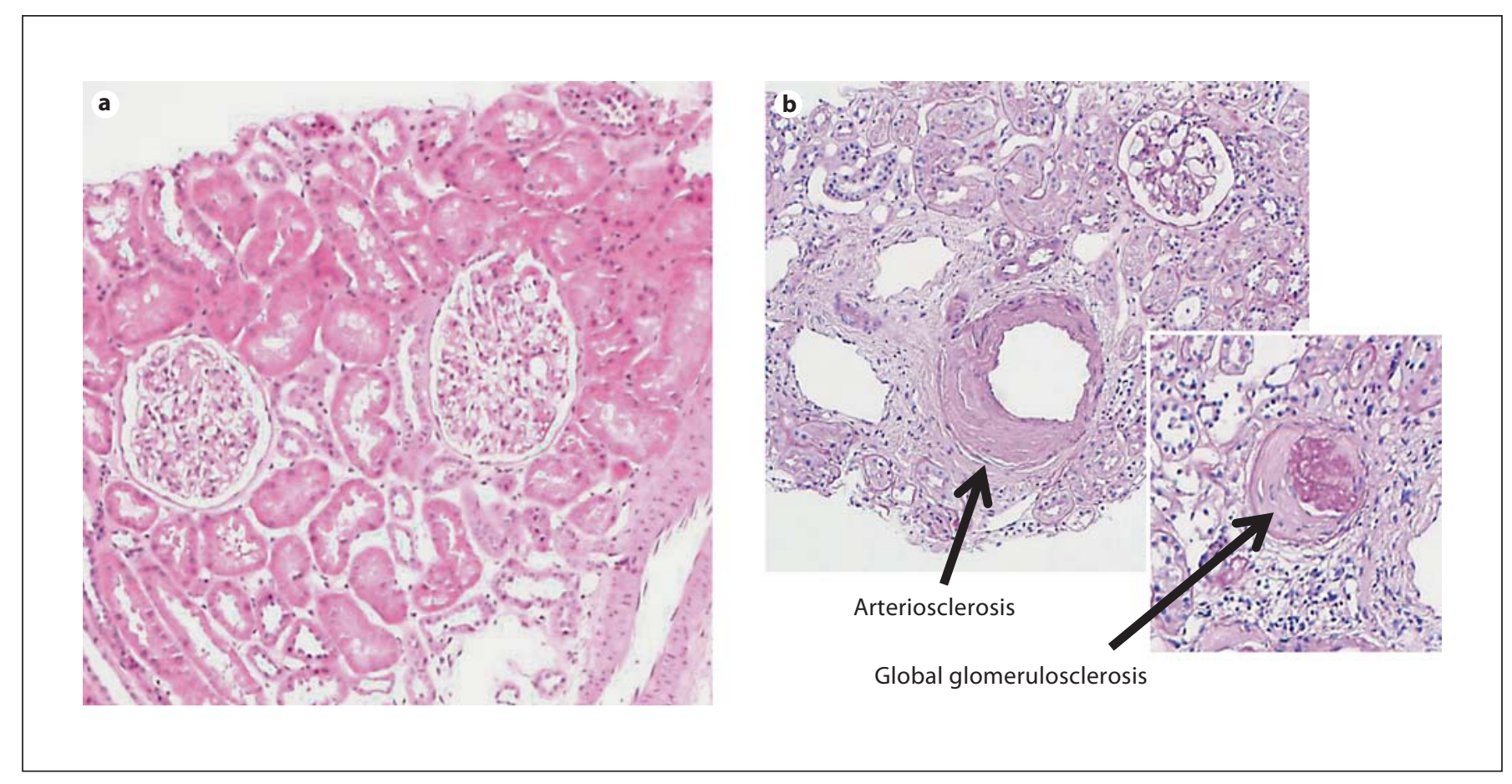

Fig. 2. The average (median) histology for 20-year-old kidney donors show no chronic histological abnormalities (a) and for 70-year-old kidney donors shows 2 different chronic histological abnormalities (b) (in this example, global glomerulosclerosis and arteriosclerosis) [10].

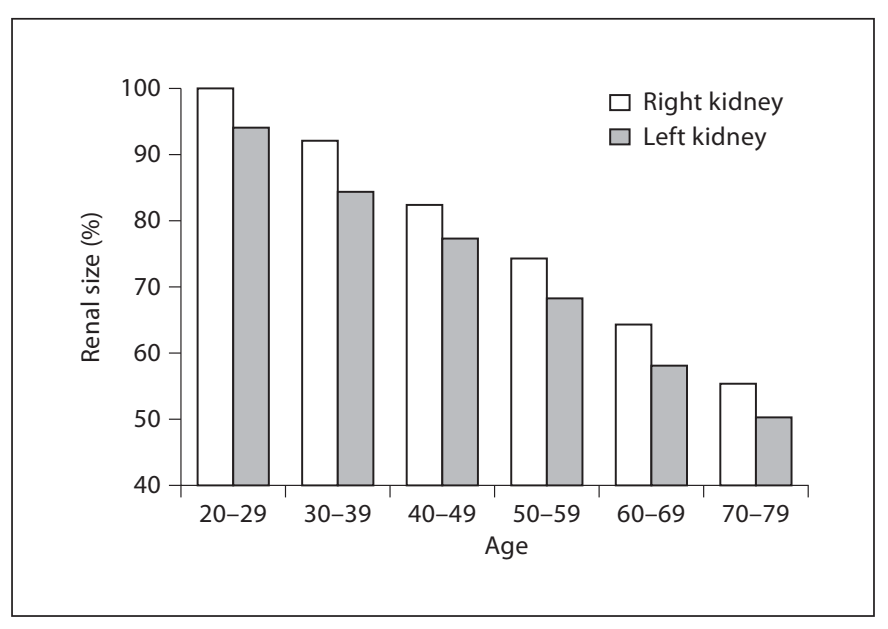

Fig. 3. Renal size by age among 360 adults without kidney disease (30 men and 30 women in each of 6 age groups). Results normalized to $100 \%$ in the right kidney of the 20 - to 29 -year age group [11]. Reprinted with permissiom from the American Journal of Roentgenology. smaller size. This process is further complicated by substantial variability in the number of glomeruli $(210,332-$ $1,825,380$ ) with which a person is born [14]. There is also evidence that the remaining nonsclerotic glomeruli hypertrophy to increase single-nephron GFR [15]. The mechanism of this compensatory glomerulomegaly with aging is not fully understood, but may itself lead to glomerular hypertension and further glomerulosclerosis [16].

Podocyte injury may also contribute to glomerulosclerosis, particularly since the normal resident podocyte does not undergo cell division [17]. In a rat transgenic model with podocytes expressing the human diphtheria toxin receptor, podocyte depletion by exposure to diphtheria toxin caused segmental and global glomerulosclerosis [18]. Podocyte hypertrophy followed by podocytopenia occurs with age in a rat model [12]. A human study found no change in the number of podocytes with age, but the fraction of podocytes compared to the total cell number in glomeruli decreased with age [19]. There is evidence of podocyte regeneration via stem cells in disease states such as crescentic glomerulonephritis, but podocyte regeneration may be inadequate in the aging glomerulus [20]. 
Living kidney donors provide a unique opportunity to gain insights into age-related changes in the renal parenchyma and to relate these changes to clinical characteristics, particularly GFR, urine albumin excretion, and blood pressure. This can be done at transplantation programs that obtain implantation biopsies of the renal allograft during the transplantation surgery. The implantation biopsy can be related to age and other characteristics of a population in generally good health. In addition, the functional and morphological changes of the remaining kidney after nephrectomy allow systematic study of the adaptive response to stress in older compared to younger kidneys [21-23]. For example, there is less compensatory increase in the volume of the remaining kidney after donation in older compared to younger donors [22]. There may be some disconnection between kidney morphology and GFR in healthy adults as the compensatory change in the remaining kidney volume does not correlate with the compensatory change in the remaining kidney GFR [22].

At the Mayo Clinic, living kidney donors across 6 decades were studied and found to have a linear GFR decline of $6.3 \mathrm{ml} / \mathrm{min} / 1.73 \mathrm{~m}^{2}$ per decade of age [10], comparable to the decline of $7.5 \mathrm{ml} / \mathrm{min}$ per decade of age reported in a longitudinal study [24]. The prevalence of nephrosclerosis (two or more findings of glomerulosclerosis, tubular atrophy, interstitial fibrosis or arteriosclerosis on renal biopsy) in this population increased linearly from $2.7 \%$ in 20 -year-olds to $73 \%$ in 70 -year-olds. Yet the decline in GFR with age did not differ between donors with or without nephrosclerosis on the kidney biopsy. In fact, age differences in GFR, treated hypertension, nocturnal blood pressure, urine albumin excretion, family history of end-stage renal disease, body mass index, serum cholesterol, glucose, and uric acid also failed to account for this dramatic increase in nephrosclerosis with aging [10]. There are three hypotheses that may explain these findings. First, sampling error with a biopsy of limited tissue [25] may fail to detect nephrosclerosis with adequate precision. Senile nephrosclerosis may occur universally, but the probability of detection on a renal biopsy depends on severity, which increases with age. Second, the decline in GFR with aging may represent a renal response to nonrenal pathology. In particular, less GFR may be needed to process metabolic waste because of age-related sarcopenia [26]. Third, the decline in GFR with aging could reflect reabsorption of glomeruli or other pathological changes in the kidney not detected by standard light-microscopic evaluation of a renal biopsy.

This last option has been explored in detail. The glomerular ultrafiltration coefficient $\left(\mathrm{K}_{\mathrm{f}}\right)$, which reflects the product of glomerular capillary surface area and glomerular water permeability, appears to decline with age. The two kidney $\mathrm{K}_{\mathrm{f}}$ estimated from GFR, renal blood flow, plasma oncotic pressure and an assumed constant transcapillary hydraulic pressure gradient were $21 \%$ lower in older compared to younger healthy adults. Likewise, the single-nephron $\mathrm{K}_{\mathrm{f}}$ estimated from structural characteristics determined from light microscopy (glomerular volume), electron microscopy (filtration surface density and filtration slit frequency) and functional studies in rats (water permeability of endothelium, basement membrane and epithelium) was $30 \%$ lower in older compared to younger kidney donors. A decreased filtration surface density and filtration slit frequency with aging suggest that a loss in water permeability within normal-appearing glomeruli may explain some of the decline in GFR with aging [27]. The occurrence of pathological changes in the kidney with age that are not readily apparent is supported by adverse changes in the recipient kidney allograft being predicted by donor age independent of the implantation biopsy histology by light microscopy [28].

However, more recent work suggests older age leads to a higher rather than lower single-nephron $K_{f}$ [29]. In a study where the mean percentage global glomerulosclerosis was $2 \%$ in younger donors compared to $17 \%$ in older donors, the single-nephron $\mathrm{K}_{\mathrm{f}}$ was $29 \%$ higher in older donors compared to younger donors. This adaptive response of hypertrophy and hyperfiltration of normal glomeruli in the aging kidney more than compensated for the global glomerulosclerosis with aging [29]. The increased size of nonsclerotic glomeruli in older kidney donors also correlates with the percentage global glomerulosclerosis present [30]. Thus, it is difficult to attribute the decline in GFR with aging to glomerulosclerosis alone. One possibility is that extensive glomerular reabsorption occurs with aging, leading to a decreased number of functioning glomeruli as estimated by two-kidney $\mathrm{K}_{\mathrm{f}}$ divided by single-nephron $\mathrm{K}_{\mathrm{f}}$ [21]. However, after nephrectomy, the one-kidney GFR increased by approximately $40 \%$ in both older and younger donors due to a proportional increase in the one-kidney $\mathrm{K}_{\mathrm{f}}$ $[21,31]$. While the GFR reserve capacity prior to donation is similar between older and younger donors, there does appear to be a loss of this reserve after donation in older donors [23]. If the remaining kidney in older donors can increase $\mathrm{K}_{\mathrm{f}}$ in response to donation, why does the aging kidney not increase $\mathrm{K}_{\mathrm{f}}$ to prevent GFR decline with aging? Since nonsclerotic glomeruli can increase their filtration rate in response to a nephrectomy, this again raises the possibility that some of the GFR decline with aging may be explained by extrarenal factors. 
The factors that control GFR at levels seemingly higher than needed for clearance of metabolic waste are not fully understood [32]. The indexing of GFR to body surface area has the implicit assumption that body surface area is the best surrogate for the metabolic waste cleared by the kidney. However, measures of nitrogen waste may be better surrogates for the metabolic waste the kidney clears. Both young and elderly healthy adults increase their GFR by about $17 \%$ with infusion of amino acids [33]. Urinary creatinine clearance is highly correlated with urinary urea nitrogen excretion and protein intake, both of which decline with age [34]. If GFR were indexed to metabolic rate or urine urea nitrogen instead of body surface area, much of the decline in GFR with normal aging would be attenuated $[34,35]$.

In conclusion, existing data do not support the viewpoint that the decline in GFR seen with normal aging is explained by a disease (nephrosclerosis) that occurs in many but not all the elderly. Nephrosclerosis could account for the decline in GFR with aging only if this pro- cess occurred universally, but then senescence rather than disease would better describe this process. Alternatively, structural changes (e.g. decreased filtration slit frequency) in nonsclerotic glomeruli or extrarenal factors could contribute to GFR decline with aging. Clearly, further studies are needed to understand age-related changes in renal morphology and function. This could have substantial implications on our understanding and management of CKD in the elderly.

\section{Acknowledgement}

This study was supported with funding from the National Institutes of Health, National Institute of Diabetes and Digestive and Kidney Disease (R01 DK 090358 and K23 DK 078229).

\section{Disclosure Statement}

The authors have no conflicts of interest to declare.

\section{References}

1 Foley RN, Wang C, Snyder IJ, Rule AD, Collins AJ: Kidney function and risk triage in adults: threshold values and hierarchical importance. Kidney Int 2011;79:99-111.

- 2 Coresh J, Selvin E, Stevens LA, Manzi J, Kusek JW, Eggers P, Van Lente F, Levey AS: Prevalence of chronic kidney disease in the United States. JAMA 2007;298:2038-2047.

- 3 O'Hare AM, Bertenthal D, Covinsky KE, Landefeld CS, Sen S, Mehta K, Steinman MA, Borzecki A, Walter LC: Mortality risk stratification in chronic kidney disease: One size for all ages? J Am Soc Nephrol 2006;17: 846-853.

-4 Swaminathan S, Leung N, Lager DJ, Melton LJ 3rd, Bergstralh EJ, Rohlinger A, Fervenza FC: Changing incidence of glomerular disease in Olmsted county, Minnesota: a 30year renal biopsy study. Clin J Am Soc Nephrol 2006;1:483-487.

-5 Briganti EM, Dowling J, Finlay M, Hill PA, Jones CL, Kincaid-Smith PS, Sinclair R, McNeil JJ, Atkins RC: The incidence of biopsyproven glomerulonephritis in Australia. Nephrol Dial Transplant 2001;16:1364-1367.

6 Albers CE: Chapter 20 - The Kidney; in Kumar V (ed): Robbins and Cotran Pathologic Basis of Disease, Professional edition, ed 8. Philadelphia, Saunders-Elsevier, 2010.

7 Kasiske BL: Relationship between vascular disease and age-associated changes in the human kidney. Kidney Int 1987;31:11531159.
8 Tracy RE, Ishii T: What is 'nephrosclerosis'? Lessons from the US, Japan, and Mexico. Nephrol Dial Transplant 2000;15:13571366

9 Zhou X, Zoltona G, Silva F: Anatomical changes in the aging kidney; in Macías Núñez JF, Cameron JS, Oreopoulos DG (eds): The Aging Kidney in Health and Disease. New York, Springer, 2008, pp 39-54.

10 Rule AD, Amer H, Cornell LD, Taler SJ, Cosio FG, Kremers WK, Textor SC, Stegall MD: The association between age and nephrosclerosis on renal biopsy among healthy adults. Ann Intern Med 2010;152:561-567.

11 Gourtsoyiannis N, Prassopoulos P, Cavouras $\mathrm{D}$, Pantelidis $\mathrm{N}$ : The thickness of the renal parenchyma decreases with age: a CT study of 360 patients. AJR 1990;155:541-544.

12 Wiggins JE, Goyal M, Sanden SK, Wharram BL, Shedden KA, Misek DE, Kuick RD, Wiggins RC: Podocyte hypertrophy, 'adaptation,' and 'decompensation' associated with glomerular enlargement and glomerulosclerosis in the aging rat: prevention by calorie restriction. J Am Soc Nephrol 2005;16:29532966.

13 Nyengaard JR, Bendtsen TF: Glomerular number and size in relation to age, kidney weight, and body surface in normal man. Anat Rec 1992;232:194-201.
14 Hoy WE, Douglas-Denton RN, Hughson MD, Cass A, Johnson K, Bertram JF: A stereological study of glomerular number and volume: preliminary findings in a multiracial study of kidneys at autopsy. Kidney Int Suppl 2003:S31-S37.

15 Samuel T, Hoy WE, Douglas-Denton R, Hughson MD, Bertram JF: Determinants of glomerular volume in different cortical zones of the human kidney. J Am Soc Nephrol 2005;16:3102-3109.

16 Brenner BM: Hemodynamically mediated glomerular injury and the progressive nature of kidney disease. Kidney Int 1983;23:647-655.

17 Lasagni L, Romagnani P: Glomerular epithelial stem cells: the good, the bad, and the ugly. J Am Soc Nephrol 2010;21:1612-1619.

18 Wharram BL, Goyal M, Wiggins JE, Sanden SK, Hussain S, Filipiak WE, Saunders TL, Dysko RC, Kohno K, Holzman LB, Wiggins RC: Podocyte depletion causes glomerulosclerosis: diphtheria toxin-induced podocyte depletion in rats expressing human diphtheria toxin receptor transgene. J Am Soc Nephrol 2005;16:2941-2952.

19 Steffes MW, Schmidt D, McCrery R, Basgen JM: Glomerular cell number in normal subjects and in type 1 diabetic patients. Kidney Int 2001;59:2104-2113.

20 Smeets B, Uhlig S, Fuss A, Mooren F, Wetzels JF, Floege J, Moeller MJ: Tracing the origin of glomerular extracapillary lesions from parietal epithelial cells. J Am Soc Nephrol 2009;20:2604-2615. 
21 Tan JC, Busque S, Workeneh B, Ho B, Derby G, Blouch KL, Sommer FG, Edwards B, Myers BD: Effects of aging on glomerular function and number in living kidney donors. Kidney Int 2010;78:686-692.

22 Jeon HG, Lee SR, Joo DJ, Oh YT, Kim MS, Kim YS, Yang SC, Han WK: Predictors of kidney volume change and delayed kidney function recovery after donor nephrectomy. J Urol 2010;184:1057-1063.

-23 Rook M, Bosma RJ, van Son WJ, Hofker HS, van der Heide JJ, ter Wee PM, Ploeg RJ, Navis GJ: Nephrectomy elicits impact of age and BMI on renal hemodynamics: lower postdonation reserve capacity in older or overweight kidney donors. Am J Transplant 2008;8:2077-2085.

24 Lindeman RD, Tobin J, Shock NW: Longitudinal studies on the rate of decline in renal function with age. J Am Geriatr Soc 1985;33: 278-285.
25 Remuzzi A, Mazerska M, Gephardt GN, Novick AC, Brenner BM, Remuzzi G: Threedimensional analysis of glomerular morphology in patients with subtotal nephrectomy. Kidney Int 1995;48:155-162.

26 Melton LJ 3rd, Khosla S, Riggs BL: Epidemiology of sarcopenia. Mayo Clin Proc 2000; 75(suppl):S10-S12; discussion S12-S13.

27 Hoang K, Tan JC, Derby G, Blouch KL, Masek M, Ma I, Lemley KV, Myers BD: Determinants of glomerular hypofiltration in aging humans. Kidney Int 2003;64:14171424.

28 Naesens M, Lerut E, de Jonge H, Van Damme B, Vanrenterghem Y, Kuypers DR: Donor age and renal P-glycoprotein expression associate with chronic histological damage in renal allografts. J Am Soc Nephrol 2009;20: 2468-2480.

29 Tan JC, Workeneh B, Busque S, Blouch K, Derby G, Myers BD: Glomerular function, structure, and number in renal allografts from older deceased donors. J Am Soc Nephrol 2009;20:181-188.

-30 Li M, Nicholls KM, Becker GJ: Glomerular size and global glomerulosclerosis in normal Caucasian donor kidneys: effects of aging and gender. J Nephrol 2002;15:614-619.
31 Saxena AB, Myers BD, Derby G, Blouch KL, Yan J, Ho B, Tan JC: Adaptive hyperfiltration in the aging kidney after contralateral nephrectomy. Am J Physiol - Renal Physiol 2006;291:F629-F634.

32 Meyer TW, Hostetter TH: Uremia. N Engl J Med 2007;357:1316-1325.

33 Fliser D, Zeier M, Nowack R, Ritz E: Renal functional reserve in healthy elderly subjects. J Am Soc Nephrol 1993;3:1371-1377.

34 Lew SW, Bosch JP: Effect of diet on creatinine clearance and excretion in young and elderly healthy subjects and in patients with renal disease. J Am Soc Nephrol 1991;2:856865.

35 Daugirdas JT, Meyer K, Greene T, Butler RS, Poggio ED: Scaling of measured glomerular filtration rate in kidney donor candidates by anthropometric estimates of body surface area, body water, metabolic rate, or liver size. Clin J Am Soc Nephrol 2009;4:1575-1583. 